\title{
Study on the influence of knowledge transfer on the ability of community residents in the development of rural tourism
}

\author{
Bo Zhou ${ }^{1}$
}

${ }^{1}$ School of International Economy and Tourism Management, Zhejiang International Studies University, Hangzhou, 310023, China

\begin{abstract}
Rural tourism is not only an important means to achieve rural revitalization, but also an important way to achieve targeted poverty alleviation and improve the living standards of community residents. In order to achieve high-quality and sustainable development of rural tourism, the key is to improve the selfmanagement ability of community residents and stimulate the endogenous force of rural tourism. Knowledge transfer can effectively improve the knowledge level and ability of community residents, improve the tourism operation and management ability of community residents in essence, and revitalize talents for the development of rural tourism. From the perspective of knowledge transfer, this article mainly studies which abilities of community residents have been improved by knowledge transfer and what impact has it had on rural tourism, which also provides a new perspective for rural tourism research.
\end{abstract}

\section{Introduction}

Rural tourism plays an important role in promoting the transformation of rural economic structure, solving the employment of rural residents and promoting the prosperity of rural economy. Looking back at the history of rural tourism development in the world, rural tourism has been given the lofty mission of rescuing rural crises and revitalizing rural economy from the very beginning (Heather, 2006) ${ }^{[1]}$. The achievements of China's rural tourism development also confirm that rural tourism plays an significant role in promoting the diversification of rural economy, expanding rural employment, promoting the comprehensive development of local social economy and revitalizing rural areas. Rural tourism has also become an important starting point for local governments to promote Rural Revitalization Strategy. However, in the practice of rural industry development, behind the booming development of rural tourism, there is a real dilemma of the bottleneck of the individual ability of community residents, which restricts the high-quality development of rural tourism to a certain extent. Tang Zhaoying $(2007)^{[2]}$ analyzed the current situation of China's rural tourism development and pointed out that talent is an important factor restricting the development of China's rural tourism. Especially under the background of industrialization and urbanization, the outflow of rural talents is serious. More and more rural labor force choose to go to the city for development, especially the loss of young people. As a result, rural talents have been in a state of "blood loss" and "anemia" for a long time, which cannot meet the needs of high-quality development of rural tourism.

Rural Revitalization Strategy points out that talent revitalization is an important guarantee of Rural Revitalization. Rural Revitalization conforms to the yearning of millions of farmers for a better life. At present, rural tourism has become an important starting point for local governments to Promote Rural Revitalization Strategy. In the development of rural tourism, local residents are the main force of Rural Revitalization. Taking rural tourism as the breakthrough point of rural revitalization, we should not only make rural community residents "rich in pocket", but also "rich in head", so as to provide guarantee for talent revitalization. At present, rural tourism talents are the weak link and the shortcoming in Rural Revitalization. Therefore, the government should promote the development of rural tourism to achieve the revitalization of the vast group of rural community residents, and the first premise is to vigorously improve the knowledge level of community residents. Knowledge transfer just creates a path for this. Knowledge transfer can effectively improve the knowledge level and personal ability of rural community residents. It is an important force to improve the tourism management ability of rural residents and make residents be a new type of modern knowledge-based residents. It provides intellectual support for the revitalization of talents. Therefore, this paper introduces the variable of knowledge into the scope of rural tourism research, and explores the specific path to improve the knowledge level and individual ability of community residents through knowledge transfer, so as to provide a new perspective for the research in the field of rural tourism, which also has important practical significance for promoting the development of rural tourism and Rural Revitalization in the new era. 


\section{Literature review}

\subsection{Rural tourism and talent revitalization}

After the 1990s, with the development of rural economy and the improvement of residents' living standards, the dominant economic motivation suffered from the impact of diversified social motivation, and the motivation and goal of rural tourism development began to break through the "shackles" of the previous mere pursuit of economic interests as the dominant goal. Residents in rural communities are eager to increase more sense of gain from the development of rural tourism, especially the improvement of personal ability. Residents in rural communities have begun to focus on pursuing selfemployment, seeking social interaction, maintaining local traditions, and enhancing hometown identity in the development of rural tourism (Luo, 2018) ${ }^{[3]}$. The practice and research of the development of the rural tourism industry have also confirmed that the development of rural tourism can promote the ability of community residents to a certain extent and realize the revitalization of talents. In the development of rural tourism, community residents are affected by tourists, market, environment and policies, and their ideological understanding, values and technical skills will also be improved(Liu , He,\& Xiang, 2018) ${ }^{[4]}$. Kline (2010) [5] found that rural tourism human resource education, training and other factors can have a significant positive impact on the development of local rural residents and tourism enterprises. Cai Kexin et al. (2018) ${ }^{[6]}$ also pointed out that community residents with certain ability and capital can improve the tourism management and reception ability, and improve the effectiveness of tourism management; on the contrary, community residents may become marginalized groups, and cause the gap between the rich and the poor in rural communities.

\subsection{Knowledge transfer and revitalization of rural tourism talents}

Knowledge transfer is a process of learning and communication, it often produces a behavior of selfreconstructing knowledge through learning and absorbing knowledge, so as to promote the absorption and reuse of knowledge(Holtham, \& Courtney,2001) ${ }^{[7]}$. Knowledge transfer means that individuals can supplement and improve others' knowledge by transferring their knowledge and experience skills. At the same time, both sides of knowledge transfer can acquire and use the knowledge provided by others to increase their own knowledge and improve their own knowledge structure (Wu, \& Zhou, 2004) ${ }^{[8]}$.From the definition of knowledge transfer, the connotation of knowledge transfer is mainly reflected in the following aspects: (1) knowledge transfer is not only an interactive activity, but also a reciprocal behavior. No matter between tourism organizations or individuals, knowledge transfer is a two-way interactive activity. At the same time, both sides of knowledge transfer increase their own knowledge and improve the interests of individuals and organizations by sharing and using the knowledge provided by each other, which reflects the connotation of mutual benefit of knowledge transfer. (2) The ultimate goal of knowledge transfer is knowledge creation and knowledge application. Both the tourism organizations and the tourism employees, because of receiving each other's knowledge and grafting their own knowledge base, apply it to the real situation and solve specific problems, realize knowledge creation in the application of knowledge, and promote the maximization of knowledge value. Thus, knowledge transfer not only increases the knowledge and skills of individuals, but also enhances the competitive advantage of organizations.

Tosun $(2000)^{[9]}$ pointed out that, especially in developing countries, if the local residents' knowledge level and operation ability are poor, local powerful people or external capital may change and directly organize to participate in tourism, so that tourism benefits will fall into the hands of a few people, and so on, which makes community participation in tourism face difficult difficulties. Therefore, improving the knowledge level and management ability of community residents is an important force to ensure the sustainable development of rural tourism and improve the tourism management efficiency of rural community residents. In the development of rural tourism, with the increase of tourists' tourism experience, their requirements and standards for rural tourism products and services become higher and higher, which also means that local residents need to innovate tourism products. Knowledge is the source of innovation, knowledge will become the driving force of rural tourism innovation and development, and knowledge transfer creates a way for community residents to improve their knowledge level and ability. In the development of rural tourism, community residents need to learn and play the power of knowledge to improve the level of tourism management and development. Knowledge transfer and sharing can help community residents accumulate the best practical experience and management methods, and promote community residents to innovate tourism products and improve the quality of tourism services.

As an important tourism destination, rural community is composed of small enterprises and organizations composed of many individuals or families. Community residents are the main body of rural community. Effective information and knowledge transfer and sharing among community residents plays an important role in the formation of tourism competitiveness of the destination. Community residents are the source of different knowledge. This also fully demonstrates the importance of knowledge transfer among residents for community and tourism development. In rural communities, community residents often participate in rural tourism in the form of individual or family, such as farmhouse, B \& B, etc. In the long-term tourism operation and management, community residents have mastered their own independent and private knowledge, accumulated their own unique experiences, and formed a variety of knowledge sources. Knowledge transfer among community residents can complement each other's knowledge structure, enrich the knowledge stock of community residents, and community residents can constantly transform and reuse the transferred knowledge in mutual learning, so as to improve the knowledge level and management skills of community 
residents, and increase the sense of tourism value acquisition.

\section{The value of knowledge transfer to improve the ability of rural tourism community residents}

\subsection{Knowledge transfer is helpful to improve the tourism service ability of community residents}

With the development of rural tourism, rural community has become an important tourism destination. Urban residents are not only eager to enjoy the beautiful rural scenery, but also eager to enjoy high-quality rural tourism services. By learning the professional knowledge and market information of tourism service, community residents can transfer and share knowledge with each other in the whole rural community, which is helpful for community residents to grasp the tourism demand of tourists, promote the tourism service ability of community residents, and improve the rural tourism service quality of the whole community.

Firstly, community residents can provide rural tourism route organization services for lodging tourists. Community residents design customized tourism routes based on the individual needs of tourists, and provide tour guide services to increase tourists' knowledge of tourist attractions; Secondly, community residents deliver host emotional services to tourists. Community residents explain the characteristics of rural culture and rural tourist attractions to tourists, so as to help tourists better understand the whole community and help tourists find nostalgia in rural tourism; third, community residents provide customized catering services to tourists. Community residents can provide customized organic food according to the dietary requirements of tourists to create a health package, which will further stimulate the revisit rate of tourists to rural areas for tourism and holiday.

\subsection{Knowledge transfer is helpful to improve the tourism management ability of community residents}

The most significant value of knowledge transfer for community residents is to improve their tourism management ability. Community residents who have accumulated successful experience can transfer and share their knowledge and experience to other community residents, while other community residents can improve the existing problems of tourism management by learning knowledge and absorbing experience, and break through the difficulties of tourism management, so as to improve the efficiency of tourism management. At the same time, returned entrepreneurs, external entrepreneurs and other talents should also actively share the skilled knowledge of tourism operation and management, promote the transfer of skilled knowledge among community residents, and help community residents achieve knowledge incremental breakthrough on the basis of knowledge stock. These knowledge and skills can be internalized into the residents' personal quality, improve the rural tourism operation and management ability of the community residents, help to shape the local residents into modern knowledge-based rural residents, and realize the local revitalization of talents. In addition, by transferring and absorbing new knowledge, community residents form a sense of mutual benefit and cooperation, build an industrial chain of mutual supply of products and sharing of tourists, and improve the tourism management ability of community residents from the aspects of thought and action as a whole.

\subsection{Knowledge transfer is helpful to improve the technology application ability of community residents}

In order to achieve high-quality development of rural tourism, rural community and community residents need to actively introduce and apply new technologies. Community residents should actively learn and apply smart technology to improve the intelligence of rural tourism management. For example, community residents should actively develop online booking channels to facilitate tourists to book rooms and order meals with one click, so as to increase the convenience of tourists' travel. Community residents use smart technology to break the original way of entering rooms with room cards, tourists merely use mobile phone to scan codes to enter rooms, so as to realize one-stop smart service of online booking and on-site swiping cards to enter rooms, so as to improve the community residents' technology application ability.

\subsection{Knowledge transfer is helpful to improve the judgment ability of community residents in rural tourism development}

The relevant policies of tourism industry represent the direction of tourism reform and development, and also represent new trend of tourism market changes. The relevant policies of tourism industry will become policy knowledge through learning. Community residents should actively learn policy knowledge, and promote the wide transfer of policy knowledge among community residents by organizing learning activities. By learning and interpreting policy knowledge, community residents can master the direction and key areas of rural tourism development, and judge the new needs and changes of tourists, which will help to improve community residents' judgment on the development of rural tourism, and then enhance the innovation ability of tourism products, tourism operation ability of community residents.

\section{Conclusion}

With the rapid development of urbanization, more and more rural youth go to work in cities to seek personal career development, which leads to the dilemma of hollowing out of rural communities and aging of surplus labor force. Rural revitalization, talent first. Rural industry depends on community residents, so does rural tourism. Reviewing the history and current situation of rural tourism development, the low level of tourism 
management knowledge and management skills of rural community residents further restricts the high-quality development of rural tourism. Due to the lack of necessary vocational training and effective management institutions, the development of rural tourism is facing many challenges. The revitalization of rural tourism not only needs the enthusiasm of community residents to pursue a rich life, but also needs to have various production skills and higher comprehensive quality.

Based on this, this paper studies how to increase the knowledge of rural community residents through knowledge transfer, so as to improve the service ability, management ability and technical ability, judgment ability of rural tourism of community residents; at the same time, rural communities should give full play to the asset effect of knowledge to realize the revitalization of rural tourism and rural talents. We must realize that it is an important force to promote the endogenous development of rural tourism to improve the knowledge level and ability of rural community residents, activate their subjective creativity in rural tourism management and get rid of their dependence on the government. The driving force and source of rural tourism development come from the local residents, so we must adhere to the road of strengthening the people with wisdom, enriching and benefiting the people, and invigorating the people with culture. At the same time, in order to better promote the development of rural tourism, we must move from "community participation" to "community led", improve the degree of organization of community and the ability of community control, so as to truly help the community residents benefit fairly from tourism, solve the poverty problem of rural communities, and truly realize the revitalization of rural areas.

\section{Acknowledgments}

This paper is one of the phased achievements of Youth program of National Natural Science Foundation of China" Differentiated formation mechanism of entrepreneurs' exit intention in sharing economy from the perspective of multiple role conflict: a study based on tourism and leisure industry" (72004195)

\section{References}

1. Heather, M.(2006). Global restructuring and local responses: Investigating rural tourism policy in two Canadian communities. Current Issues in Tourism, 9(1):1-46.

2. Tang Z.Y., Yang N.G. (2007). On the dynamic mechanism and Sustainable Development Countermeasures of suburban rural tourism development. Agricultural Environment and Development, (6): 36-38

3. Luo Z.G.(2018).Rural Revitalization in foreign countries: Value orientation and strategy selection -- a reference for the implementation of Rural Revitalization Strategy in China. Agricultural Science Research,39 (4): 84-90+94

4. Liu C.W., He W.J., Xiang Y.C.(2018).Rural
Revitalization from the perspective of rural tourism. Chongqing Social Sciences, 286(9): 96-105

5. Kline C., Milburn L.A.(2010).Ten categories of entrepreneurial climate to encourage rural tourism development. Leisure Studies Journal, 13(1-2): 320348.

6. Cai K.X., Yang H., Ma Z.Z.(2018).Rural Tourism: a way to realize Rural Revitalization Strategy. Rural Economy, 431 (09): 28-33

7. Holtham C., Courtney N.(2001).Developing managerial learning styles in the context of the strategic application of information and communications technologies. International Journal of Training \& Development, 5(1): 22-34.

8. Wu X.L., Zhou M.(2004).Knowledge transfer and its difficulties within organizations. Science of Science and Management of S.\& T., 25 (12), 68-71

9. Tosun C .(2006).Limits to Community Participation in the Tourism Development Process in Developing Countries. Tourism Management, 21(6): 613-633. 